\title{
Método mãe canguru: um contato de amor e carinho - atuação do enfermeiro na orientação desse método
}

\author{
Sabrina Ferreira de Oliveira*, Inês Maria Meneses dos Santos**
}

*Enfermeira, Escola de Enfermagem Alfredo Pinto - UNIRIO, ** Professora Adjunta do Departamento de Enfermagem Materno-Infantil da Escola de Enfermagem Alfredo Pinto - UNIRIO

\begin{abstract}
Resumo
Trata-se de um estudo descritivo com abordagem qualitativa. Apresenta como objetivo: Analisar as orientaçóes de enfermagem sobre o método mãe canguru na perspectiva dos enfermeiros que atuam na unidade intermediária neonatal de uma maternidade do Município do Rio de Janeiro. Os dados foram coletados entre os meses de setembro e novembro de 2007, por meio de uma entrevista contendo questóes abertas sobre o método canguru. Os sujeitos entrevistados foram seis enfermeiros neonatologistas. O cenário escolhido foi uma maternidade pública do município do Rio de Janeiro. Posteriormente, foram criadas duas categorias temáticas: 1) O contato entre máe-bebê estimulado pelo enfermeiro, como parte da assistência ao recém-nascido de baixo peso e/ou prematuro; 2) Capacitação do enfermeiro sobre o método canguru. Concluiu-se que ainda existe uma parte considerável de enfermeiros que resistem em utilizar as orientaçóes sobre o método canguru, como parte da assistência de enfermagem.
\end{abstract}

Palavras-chave: recém-nascido de baixo peso, prematuro, método canguru, enfermagem neonatal.

\section{Abstract \\ Kangaroo mother method: a contact of love and affection - nurse performance to guide this method}

This descriptive study with qualitative approach had as objective: to analyze, from nurses perspective, information received from the nursing staff of a neonatal maternity of Rio de Janeiro city concerning kangaroo mother method. Data were collected between September and November 2007, by means of an interview which contained opened questions about the kangaroo method. The interviewed subjects were six neonatal nurses. The research scenery was a public maternity of Rio de Janeiro city. Two thematic categories were created: 1) the skin-to-skin contact between mother and baby encouraged by nurse, as part of low birth-weight infants and/or premature care; 2) qualified nurse on the kangaroo method. We conclude that there is still a resistance to this method and a considerable number of nurses do not include kangaroo method guidelines in their neonatal services.

Key-words: low birth-weight newborn, premature, kangaroo method, neonatal nursing.

Artigo recebido em 25 de novembro de 2008; aceito em 5 de maio de 2009. Endereço para correspondência: Sabrina Ferreira de Oliveira, Rua Afonso Cavalcanti 455/701, 20211-901 Rio de Janeiro RJ, Tel: (21) 8790-1926, E-mail: sabrinaferreira1986@ig.com.br, inesmeneses@gmail.com 


\section{Resumen \\ Método madre canguro: un contacto de amor y de afecto - actuación de la enfermera en la orientación de este método}

Se trata de un estudio descriptivo con abordaje cualitativo que tiene como objetivo: analizar las orientaciones de enfermería sobre el método madre canguro en la perspectiva de los enfermeros que actúan en la unidad neonatal intermedia de una maternidad de la ciudad de Rio de Janeiro. Los datos fueron colectados entre los meses de Septiembre y Noviembre de 2007, por medio de una entrevista conteniendo preguntas abiertas sobre el método madre canguro. Los ciudadanos entrevistados fueran seis enfermeros neonatólogos. El escenario escogido fue una maternidad pública de la ciudad de Rio de Janeiro. Posteriormente, dos categorías temáticas fueron creadas: 1) El contacto entre la madre y el bebé estimulado por el enfermero, como parte de la asistencia al recién nacido de bajo peso y/o prematuro; 2) Capacitación del enfermero sobre el método madre canguro. Se concluye que todavía una gran parte de enfermeros resisten en usar las orientaciones sobre el método madre canguro, como parte del cuidado de enfermería.

Palabras-clave: recién nacido de bajo peso, prematuro, método canguro, enfermería neonatal.

\section{Introdução}

O método "Mãe-Canguru" foi criado em 1979, na Colômbia, buscando um atendimento melhor, humanizado e de menor custo, tanto para o recém-nascido de baixo peso quanto para seus familiares. Entende-se por recém-nascido de baixo peso aquele que nasceu com peso inferior a $2500 \mathrm{~g}$, independente da idade gestacional. E prematuro é aquele recém-nascido que não completou 37 semanas de gestação, independente do peso [1].

O método consiste em um tipo de assistência neonatal que implica contato pele a pele precoce entre máe e o recém-nascido de baixo peso, pelo tempo que ambos acharem prazeroso e suficiente, permitindo, dessa forma, uma maior participação dos pais no cuidado a seu recém-nascido. A posição canguru consiste em manter o recém-nascido de baixo peso, ligeiramente vestido, em decúbito prono, na posiçáo vertical, contra o peito do adulto [2]. A posiçáo vertical é utilizada para se evitar o refluxo gástrico-esofágico e a bronco-aspiração, fenômenos comuns que podem levar à asfixia e até mesmo à morte.

As vantagens desse método são aumentar o vínculo mãe-filho, evitar longos períodos sem estimulação sensorial, estimular o aleitamento materno, aumentar a competência e confiança dos pais no manuseio do seu filho, proporcionar melhor controle térmico, melhorar o relacionamento da família com a equipe de saúde, diminuir a infecção hospitalar e a permanência hospitalar [3]. O método canguru favorece o início e a manutenção da lactação, pois a proximidade constante com a máe, seus movimentos e seu cheiro, contribuem para estimular a produçáo de leite [4]. Não substitui as unidades de terapia intensiva (UTIs) neonatais nem as incubadoras, mas sim supre as necessidades do RN levando ao desenvolvimento, proporcionando o aleitamento materno, calor da mãe, carícias, enfim, as influências humanas que contribuem na recuperação do $\mathrm{RN}$ internado, condiçóes estas náo viabilizadas pelos equipamentos da UTI neonatal [3].

Interessado em humanizar a assistência prestada aos recém-nascidos de baixo peso, o Ministério da Saúde lançou, por meio da Portaria no 693 de 5/7/2000, a Norma de Atenção Humanizada do Recém-Nascido de Baixo Peso (Método Canguru) [2].

O interesse pelo método Mãe Canguru surgiu a partir da exibição de um material áudio-visual, durante a disciplina de Enfermagem na Atenção à Saúde do Recém-nascido, da Escola de Enfermagem Alfredo Pinto, da Universidade Federal do Estado do Rio de Janeiro (UNIRIO).

Durante a vivência acadêmica observa-se que o profissional enfermeiro não utiliza a prática sistemática de orientação às mães, como ferramenta que compóe a assistência de enfermagem aos recém-natos prematuros ou de baixo peso. A partir daí resolvemos elaborar um estudo cujo objeto é a atuação do(a) enfermeiro(a) na orientação à mãe de recém-nascido em método mãe canguru.

O objetivo traçado foi analisar as orientaçóes de enfermagem sobre o método mãe canguru na perspectiva dos enfermeiros que atuam na unidade intermediária neonatal de uma maternidade do Município do Rio de Janeiro. 
Quanto à relevância, aponta-se a importância do papel do enfermeiro para o sucesso do método máe-canguru, enquanto modalidade de assistência humanizada e integral.

\section{Material e métodos}

Trata-se de uma pesquisa com abordagem qualitativa, pois surge diante da impossibilidade de investigar e compreender, por meio de dados estatísticos, alguns fenômenos voltados para a percepção, a intuição e a subjetividade [5]. O estudo é descritivo, já que apresenta como finalidade a descrição exata de fatos e fenômenos de determinada realidade, o que exige do pesquisador uma série de informaçóes sobre o que se deseja pesquisar [5].

Foi solicitada autorização à direção da instituição para a realização desta pesquisa e, posteriormente, o projeto foi encaminhado ao Comitê de Ética em Pesquisa da Secretaria Municipal de Saúde do Rio de Janeiro, sendo aceito sem ressalvas, sob o protocolo número 104/07.

Obedecendo a Resolução 196/96 diretrizes e normas regulamentadoras de pesquisa envolvendo seres humanos, do Conselho Nacional de Saúde foi entregue o Termo de Consentimento Livre e Esclarecido, informando sobre os objetivos, anonimato e participação em caráter voluntário na pesquisa. Somente após o consentimento do entrevistado, com a assinatura do termo, é que se procedeu a entrevista.

A coleta dos depoimentos foi realizada por meio de entrevista, utilizando um questionário (anexo) preenchido pela pesquisadora, o qual continha questóes abertas versando sobre o método canguru, além de dados de identificaçáo dos depoentes. As entrevistas foram realizadas durante os meses de setembro e novembro de 2007 , até que fosse atingido um ponto de saturação.

O cenário foi uma unidade neonatal que possui enfermaria canguru, localizada em uma maternidade pública do município do Rio de Janeiro.

\section{Resultados e discussão}

Os sujeitos entrevistados foram seis enfermeiros, com especialização em Neonatologia. Para garantir o anonimato dos entrevistados, optou-se por identificá-los por meio de pseudônimos, sendo escolhido para tal, nomes de escritores brasileiros.

Optou-se por construir um quadro abaixo, mostrando a caracterização dos entrevistados.
Quadro I - Caracterização dos enfermeiros entrevistados.

\begin{tabular}{|l|l|l|l|}
\hline Pseudônimo & Especialização & $\begin{array}{l}\text { Tempo de } \\
\text { formado }\end{array}$ & $\begin{array}{l}\text { Tempo de } \\
\text { atuação na } \\
\text { unidade } \\
\text { neonatal }\end{array}$ \\
\hline $\begin{array}{l}\text { Machado de } \\
\text { Assis }\end{array}$ & Neonatologia & 9 anos & 8 anos \\
\hline Zélia Gattai & Neonatologia & 6 anos & 6 anos \\
\hline $\begin{array}{l}\text { Clarice Lis- } \\
\text { pector }\end{array}$ & Neonatologia & 14 anos & 10 anos \\
\hline Jorge Amado & Neonatologia & 3 anos & 2 anos \\
\hline $\begin{array}{l}\text { Rachel de } \\
\text { Queiroz }\end{array}$ & Neonatologia & 15 anos & 10 anos \\
\hline $\begin{array}{l}\text { José de Alen- } \\
\text { car }\end{array}$ & Neonatologia & 5 anos & 2 anos \\
\hline
\end{tabular}

Fonte: Unidade neonatal com enfermaria canguru de uma maternidade pública do Município do Rio de Janeiro.

As entrevistas foram lidas exaustivamente $\mathrm{e}$ realizada a análise temática. Foram construídas duas categorias analíticas, a partir dos depoimentos: 1) o contato entre mãe-bebê estimulado pelo enfermeiro, como parte da assistência ao recém-nascido de baixo peso e/ou prematuro; 2) capacitação do profissional sobre o método mãe-canguru.

Categoria I - O contato entre mãe-bebê estimulado pelo enfermeiro como parte da assistência ao recém-nascido de baixo peso e/ou prematuro

Sabemos que o(a) enfermeiro(a) mantém um contato maior com as máes e os recém-nascidos internados. Desse modo, cabe ao profissional orientar às máes sobre o método canguru, bem como sobre a situação clínica do recém-nato; os equipamentos que estâo ao redor dele, com a intenção de tranqüilizar os familiares do bebê, minimizando seu estresse, favorecendo o vínculo entre mãe e bebê.

Desde o início dos anos 80, vários estudos têm atribuído importância especial ao aspecto psicológico, ao contato pele a pele entre a mãe e seu bebê. Assim, espera-se que haja um vínculo mãefilho muito maior, que auxilie o desenvolvimento psicomotor dos recém-nascidos, notadamente os de baixo peso [1].

A orientação à mãe sobre os benefícios do método canguru é uma forma interessante encontrada para que os enfermeiros estimulem o contato entre mãe-bebê. 
"São orientadas questóes como a posição correta do método; o estímulo ao aleitamento; o ganho de peso e a redução de problemas respiratórios. Falando das coisas boas do método é a principal 'arma' que uso para estimular a mãe a realizar o método." Zélia Gattai

O enfermeiro deve encorajar as mães a concentrar-se no recém-nascido e nos sentimentos e emoçôes, para melhor obtenção de benefícios emocionais e fisiológicos do método. Porém, todo esse aspecto nem sempre é levado em consideraçáo por parte de alguns profissionais.

Existe certa resistência por parte de alguns enfermeiros com relação à questão da orientaçáo do método canguru, como pode ser observado nos relatos a seguir.

\footnotetext{
"No nosso setor, as crianças estão em estado bem crítico. No plantão de hoje, sou o único enfermeiro da equipe. Não temos muito tempo disponível para orientar quanto ao método canguru." Jorge Amado

"Com tanto procedimento para ser feito, o estresse é tão alto que não 'rola' tempo para conversar com os familiares." Rachel de Queiroz
}

O mundo globalizado de hoje, exige profissionais cada vez mais capacitados, principalmente do ponto de vista tecnológico, exigindo atributos e conhecimentos dos trabalhadores para responder às demandas impostas pelas mudanças sociais e econômicas. Nesse contexto as interaçóes pessoais acabam por assumir uma condição inferior [6].

O método deve ser visto como um instrumento que compóe a intensa gama de atividades da assistência de enfermagem ao bebê, e não como uma forma de retirar a responsabilidade do profissional enfermeiro quanto ao cuidado com o recém-nascido, distribuindo esse encargo somente à mãe. Isso pode ser evidenciado no seguinte relato.

"Oriento a equipe o tempo todo a exercer o método. Eu explico a importância dele, mostrando a possibilidade de diminuiçáo do cuidado da equipe com o bebê." Clarice Lispector.

\section{Categoria II - Capacitaçáo do enfermeiro sobre o método canguru}

O Ministério da Saúde elaborou o Manual Técnico do Método Canguru, com base na Norma de Atenção Humanizada ao Recém-nascido de Baixo Peso (Método Canguru), como uma forma importante de dirigir esforços para propiciar uma atenção de qualidade ao recém-nascido prematuro ou de baixo peso e aos seus familiares. Surgiu, então, a necessidade de desenvolver uma estratégia para a sua implementação nas diversas unidades hospitalares. Sendo assim, uma nova equipe de consultores, juntamente com os técnicos da área da Criança do Ministério da Saúde desenvolveram um programa de treinamento teórico-prático sobre Atenção $\mathrm{Hu}$ manizada ao Recém-nascido de Baixo-Peso (Método Mãe Canguru). Esse curso, idealizado para ser oferecido em 40 horas de duração, objetivou capacitar os profissionais das diferentes especialidades que lidam com o recém-nascido de baixo-peso, sua mãe e sua família [7].

\section{"A Secretaria Municipal de Saúde oferece curso sobre o método mãe-canguru na própria uni- dade. São feitas também palestras. A própria Secretaria e a Unesco passam visita na unidade, avaliando o grau de conhecimento da equipe sobre o método." Machado de Assis}

"A Secretaria Municipal de Saúde está promovendo palestras sobre o tema, aqui tem muita gente falando disso.” Zélia Gattai

O município do Rio de Janeiro cumpre com seu papel ao apoiar os cursos de capacitação dos profissionais envolvidos na assistência neonatal, podemos perceber isso nas falas supracitadas de alguns entrevistados.

Apesar do acesso às informações sobre o método, na maior parte das vezes gratuito, muitos profissionais não procuram ampliar seus conhecimentos sobre o tema.

\footnotetext{
"Nunca me interessei. É um método bonito, humanizado, mas prefiro estudar algo que aplico na realidade.” Rachel de Queiroz

"Durante a especialização tive algumas palestras sobre isso, mas não fiz nenhum curso sobre o método.” Jorge Amado
} 
É necessário que os profissionais de saúde conheçam toda a extensão do método e se capacitem sempre quanto aos novos e alternativos meios de cuidado ao bebê, para que assim possam prestar uma assistência de qualidade.

\section{Conclusão}

Prestar assistência ao recém-nascido de baixo peso ou prematuro envolve a necessidade de disponibilidade tanto de recursos materiais quanto de recursos humanos especializados. Mas, acima de tudo é preciso que o(a) enfermeiro(a) tenha sensibilidade quanto à comunicação não-verbal emitida pelos bebês. Logo, é preciso criar uma assistência de enfermagem integral e humanizada.

O método mãe canguru traz muitos benefícios tanto para o recém-nascido prematuro e/ou de baixo peso quanto para seus familiares, pois a oportunidade de cuidar do bebê aumenta o vínculo entre os pais e a criança. Trata-se de uma modalidade de assistência simples, de baixo custo e eficaz. Porém, para que o método seja eficaz é necessário que a equipe de enfermagem conheça toda a extensáo e importância do método e esteja adequadamente treinada para que possa orientar adequadamente a mãe do recém-nascido que deve sentir-se acolhida. Desse modo, em caso de dúvidas, sentir-se-á à vontade para recorrer ao profissional enfermeiro que deve mostrar-se solícito em atender à mãe. Os enfermeiros náo devem apenas limitar-se aos aspectos técnicos do método, mas também devem enxergar a mãe do bebê como sendo uma mulher que possui conflitos, emoções e sentimentos. Essa relação de confiança entre a mãe e o profissional é de fundamental importância para a obtenção do sucesso do método canguru.

Com este estudo conclui-se que a maioria dos enfermeiros entrevistados acredita e apóia o uso das orientaçôes sobre o método, como forma de assistência humanizada ao recém-nascido prematuro e/ou de baixo peso. Mas, ainda existe uma determinada parcela de profissionais que apresenta resistência em realizar o método canguru como modalidade de assistência de enfermagem neonatal.

\section{Referências}

1. Whaley LF, Wong DL. Enfermagem pediátrica: elementos essenciais à intervenção. $5^{\mathrm{a}}$ ed. Rio de Janeiro: Guanabara Koogan; 1999.

2. Brasil. Ministério da Saúde. Atenção Humanizada ao recém-nascido de baixo peso - método mãe - canguru. Manual técnico. Brasília: MS; 2002.

3. Ferreira L, Vieira CS. A influência do método - canguru na recuperação do recém-nascido em Unidade de Terapia Intensiva Neonatal: uma revisão de literatura. Acta Scientiarum Health Sciences 2003;25(1):41-50.

4. Caetano LS, Borçari IT, Vilaça CM, Santos JA. O posicionamento canguru e amamentação de recém-nascidos a termo. Enfermagem Brasil 2006;5:337-40.

5. Figueiredo NMA. Método e metodologia na pesquisa científica. São Paulo: Difusão; 2004

6. Oriá MOB, Moraes LMP,Victor JF. A comunicação como instrumento do enfermeiro para o cuidado emocional do cliente hospitalizado. Revista Eletrônica de Enfermagem; 2004;06(2).

7. Oliveira ND. O que é a norma brasileira de atenção humanizada ao recém-nascido de baixo peso (método mãe-canguru)- 2000 [online]. [citado 2006 Dez 28]. Disponível em URL: www.metodocanguru.org.br/ funciona.htm

8. Brasil. Ministério da Saúde. Conselho Nacional de Saúde. Resolução 196, de $1^{\circ}$ de Outubro de 1996 - dispóe sobre pesquisa envolvendo seres humanos. Brasília: MS; 1996.

\begin{tabular}{|l|}
\hline \multicolumn{1}{|c|}{ Anexo } \\
\hline Entrevista para a(o) enfermeira(o) \\
Identificação (iniciais): \\
Idade: \\
Tempo de formado: \\
Tempo de trabalho na Unidade Neonatal: \\
Pós-graduação: ( ) não ( )sim, em que? \\
\hline 1- Quais as orientaçães que a equipe de enfermagem passa para as mães dos recém-nascidos prematuros ou de \\
baixo peso sobre o método canguru? \\
\hline 2- Como a equipe de enfermagem estimula o contato entre essa mãe e o seu bebê? \\
\hline 3- Você fez algum treinamento voltado para a aplicação do método? \\
\hline $\begin{array}{l}\text { 4- Você encoraja a equipe a exercer o método como parte da assistência de enfermagem ao RN de baixo peso ou } \\
\text { prematuro? Como? }\end{array}$ \\
\hline
\end{tabular}

